\title{
Coil Occlusion of Coronary Cameral Fistula: A Case Report
}

\author{
NNF Begum ${ }^{1}$, AFM Shamsul Haque ${ }^{2}$, MF Rahman ${ }^{1}$ \\ ${ }^{1}$ Department of Pediatric Cardiology, CMH, Dhaka, ${ }^{2}$ Department of Cardiology, CMH, Dhaka
}

\begin{abstract}
:
Keywords:

Coronary

Cameral Fistula,

Coil occlusion.

Congenital coronary artery fistula is a rare anomaly that can cause several types of morbidity and mortality. Interventional occlusion of coronary artery fistula has become a well-accepted alternative to surgical therapy. A coronary cameral fistula originating from right coronary artery (RCA) and draining to right atrium (RA) was occluded with a detachable coil in a two years old girl in catheterization laboratory of Combined Military Hospital (CMH) Dhaka. This is the first ever case of coil occlusion of coronary cameral fistula in Bangladesh, which led to the writing of this report.
\end{abstract}

(Cardiovasc. j. 2011; 3(2): 218-221)

\section{Introduction:}

Coronary artery fistulas (CAFs) are the communication between coronary artery and the system (artery or vein) or the pulmonary artery (including the coronary sinus) or any of the four cardiac chambers of the heart. If the connection is to one or multiple chamber of the heart, it is termed a coronary-cameral fistula. ${ }^{1}$ It constitute $0.2-0.4 \%$ of all congenital cardiac defects. The incidence is similar between males and females. Most of the patients with coronary artery fistulae are asymptomatic. On the other hand shunt through fistula can be so large that congestive heart failure occurs. In young adults, symptoms like atrial fibrillation, fatigue, exertional dyspnoea or ischaemic chest pain may appear but symptoms are usually rare before 20 years of age. ${ }^{2,3}$ Angina pectoris is seen in $80 \%$ of these patients after 50 years of age. Color Doppler Echocardiography is the diagnostic test by which dilated coronary artery and the fistula including its entry point can be visualized. Most of the fistulae including small ones should be closed to prevent infective endocarditis, congestive cardiac failure and myocardial ischaemia. Surgical ligation of fistula has long been established. Percutaneous coil embolization or closure with vascular plug is gaining rapid popularity as these are safe, effective and patient can avoid thoracotomy scar and long invasive procedure as well.

\section{Case report:}

' $T$ ', a two years old male child was diagnosed as a case of coronary cameral fistula from right coronary artery (RCA) to right atrium (RA) since twenty third month of his age. He had history of recurrent respiratory tract infection since early infancy along with failure to thrive. In one occasion of respiratory infection one month ago, a pediatrician saw him and murmur was detected. He was referred to pediatric cardiologist of Combined Military Hospital (CMH) Dhaka and cardiac work up was done. His ECG showed left ventricular hypertrophy (LVH) and chest X-ray showed mild cardiomegaly with plethoric lungs field. Echocardiography of 'T' with color Doppler

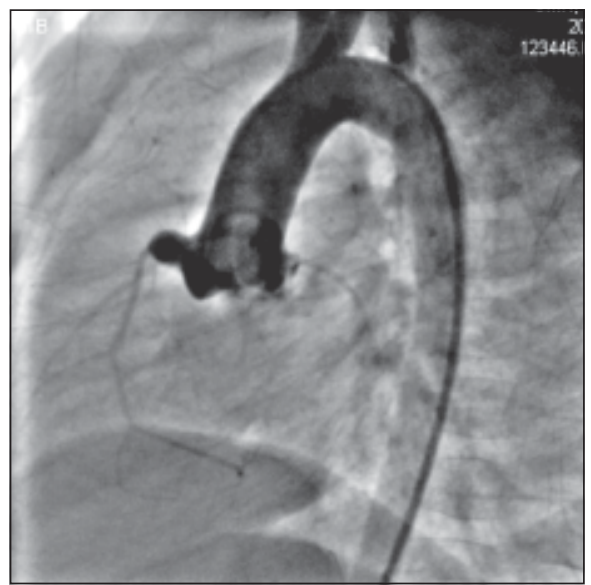

Fig.-1: Origin of coronary fistula from right coronary sinus.

Address of Correspondence: Dr. Nurun Nahar Fatema Begum, Paediatric Cardiologist, Lab Aid Cardiac Hospital,Dhaka. e-mail colfatema@hotmail.com. 
detected a fistulous communication between right coronary artery and right Atrium with left to right shunt. He was treated initially with anti-failure medicines for about a month and than he was taken into the catheterization laboratory of Combined Military Hospital (CMH) Dhaka on $15^{\text {th }}$ August 2010 with an intention of trans catheter closure of fistula with detachable PDA coil.

\section{Procedure Equipments:}

1. JR, Cook, Multipurpose and Pigtail catheter.

2. Normal pediatric drape and puncture set.

3. PDA coil, size $5 \mathrm{x} 4$, coil delivery system.

Procedure was performed under deep sedation with injection Ketamine and Diazepam. After draping, right femoral artery and vein were cannulated with $5 \mathrm{~F}$ and $6 \mathrm{~F}$ sheath. Aortogram was performed in

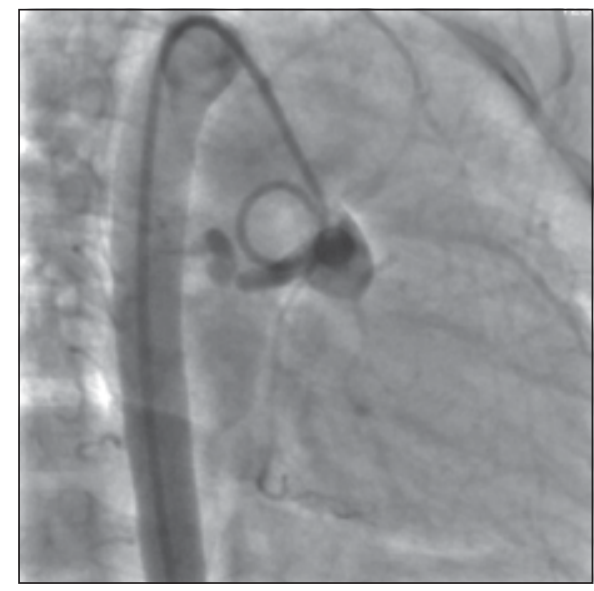

Fig.-2: Narrowest part of the coronary cameral fistula from RCA to RA.

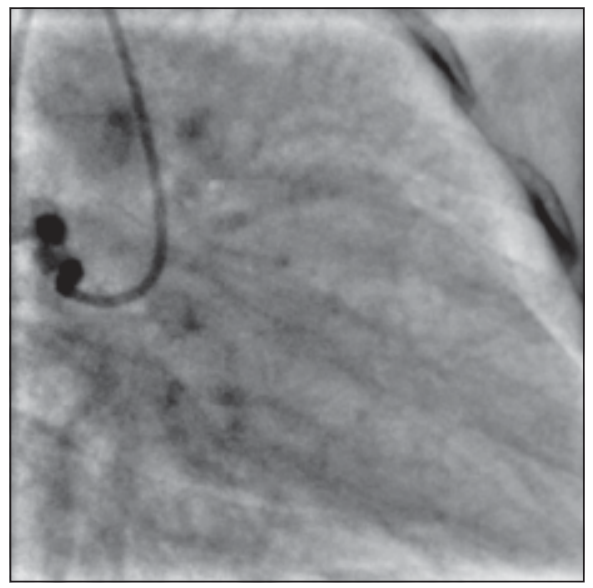

Fig.-3: JR4 catheter engaged to right coronary sinus. different view to bring the entire course of fistula in good profile. RCA was engaged with JR-4 catheter and was exchanged with Cook 5F multipurpose catheter. Narrowest point of the fistula was $2.5 \mathrm{~mm}$. So a $5 \mathrm{x} 4 \mathrm{~mm}$ coil (Cook coil) was loaded in the delivery cable. Delivery cable was than forwarded through the catheter and narrowest point was crossed. Appropriate position was checked by dye injection using Manifold. Two of the coils were delivered distal to the narrowest part towards the right atrium and rest two coils were released proximal to the narrowest part and towards RCA. Precaution was taken not to occlude any of the branch of the right coronary artery and to hamper coronary circulation. Coil was than released from the delivery cable by unscrewing. Aortogram performed with pigtail showed total occlusion of the fistula and patency of the right coronary system.

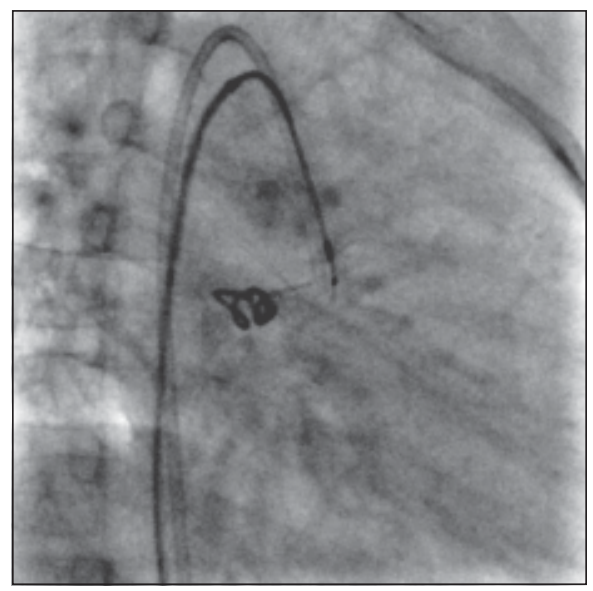

Fig.-4: PDA coil attached to delivery cable.

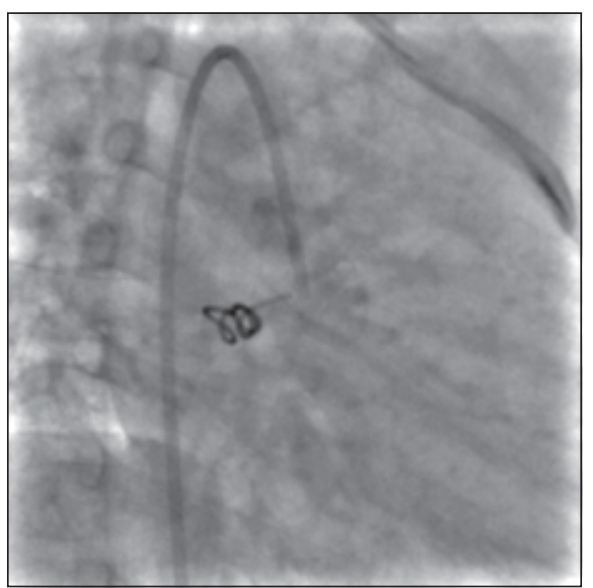

Fig.-5: PDA coil detached from delivery cable, stable in position. 
ECG and cardiac enzymes were done 6 hours and 12 hours after the procedure and was normal. Echocardiogram showed no residual fistulous communication. Patient was discharged 48 hours after the procedure.

\section{Discussion:}

A coronary cameral fistula is a rare anomaly involving a vascular communication between a coronary artery and a cardiac chamber. They are often caused by aberrancies of normal embryological development. ${ }^{4}$ The major sites of fistula are the right coronary artery (55\%), left coronary artery (35\%), and a combination of both coronary arteries (5\%). Termination sites are the right ventricle (40\%), right atrium (26\%), pulmonary arteries (17\%) and less frequently, the superior vena cava or coronary sinus. ${ }^{5-7}$ Most coronary fistula are congenital, and these are the most haemodynamically significant primary coronary anomalies. ${ }^{5}$ The clinical features depends on size and site of the fistula which ranges from a continuous murmur in asymptomatic children to congestive heart failure in symptomatic infants. ${ }^{8,9}$ Coronary fistula can be closed either surgically or by trans catheter approach. ${ }^{10,11,12}$ Trans catheter approach has definite advantage over surgical ligation. Trans catheter approach is a low cost procedure with less morbidity and hospital stay and moreover thoracotomy can be avoided. ${ }^{13}$ There are various techniques for trans catheter closure which includes coil embolization and vascular plug etc. ${ }^{14,15}$ If fistula left untreated then there will be chance of myocardial ischaemia, thromboembolization, aneurismal dilatation, endarteritis, congestive cardiac failure, arrhythmia and rupture. ${ }^{16,17}$ Though most of the fistula can be closed by interventional technique, complications like distal embolization of coil or dissection have been reported. ${ }^{18,19}$ Amplatzer vascular plug is a very good device for closing coronary fistula, but considering the small diameter of the narrowest part of the fistula in this case near right atrium, PDA detachable coil was used. The successful out come of this case suggest that coil embolization is a safe and cost elective mean for closing coronary cameral fistula.

\section{Conclusion:}

Interventional occlusion of coronary artery fistula has become a well accepted alternative to surgical therapy in many centers. In present case myocardial enzyme analysis, electrocardiography and wall motion in echocardiography was completely within normal limit with in 48 hours of the procedure. So this procedure has proved itself as effective one in our center also.

\section{References:}

1. Levin DC, Fellows KE, Abrams HL. Haemodynamically significant primary anomalies of the coronary arteries: angiographic aspects. Circulation 1987;58:25-34.

2. Gasul BM,Arcilla RA, Fell EH, Lynfield J,Bicoff JP,Luan LL. Congenital coronary arteriovenous fistulae:Clinical,phonocardiographic,angiocardiographic and haemodynamic studies in 5 patients . Paediatrics 1960;25:531-560.

3. Ludomirsky A, O'laughin NP, Reul GJ, Mullins CE. Congenital aneurysm of the right coronary artery with fistulas connection to the right atrium. Am Heart $J$ 1990;119:672-675.

4. S. E Kassaian, M Ali doosti, H Sadeghian, M R Dehk ordi. Transcatheter closure of a coronary fistula with an Amplatzer (R) vascular plug. Tex Heart Inst J 2008; 35 (01): 58-61.

5. Wiegan G, Seiverding L, Kaulit R, Hofbeck M. Transarterial and transvenous approach for transcatheter closure of a large coronary artery fistula with the Amplatzer vascular plug. Pediatr Cardiol 2009; 30 (2): 172-5.

6. Kilic H, Akdemir R, Bicer A, Dogan M. Transcatheter closure of congenital coronary arterial fistulas in adults. Coron Artery Dis 2008; 19 (1): 43-5.

7. Holzer R, Johnson R, Coitti G, Pozzi M, Kitchiner P. Review of an institutional experience of coronary arterial fistulas in childhood set in context of review of the literature. Cardiol Young 2004; 14 (4): 380-5.

8. Ragnarsson A, Emanuelsson H. Treatment of a large congenital coronary fistula with coil embolization. Scand Cardiovasc J 1999; 33 (1): 57-9.

9. Levin DC, Fellows KE, Abrams HL, Hemodynamically significant primary anomalies of the coronary arteries. Angiographic aspects. Circulation 1978; 58 (1): 25.34.

10. Sherwood MC, Rockenmacher S, Colan SD, Geva T. Prognostic significance of clinically silent coronary artery fistulas. Am J Cardiol 1999; 83 (3): 407-11.

11. Armsby LR, Keane JF, Sherwood MC, Forbess JM, Perry SB, Lock JE. Management of coronary artery fistulae. Patient selection and results of transcatheter closure. J Am Coll Cardiol 2002; 39 (6): 1026-32. 
12. Malekahmadi M, Shahmohammadi A. Surgical outcome of coronary artery fistulas repair in children. Pediatr Cardiol 2005; 26 (4): 328-30.

13. Qureshi SA, Tynan M. Catheter closure of coronary artery fistulas. J Interv Cardiol 2001; 14 (3): 299-307.

14. Diaz de la Liera LS, Fournier Andray JA, Gomes Moreno S, Mayol Deya A, Gonzalez Garcia A, Perez FernandezCortacero JA. Paercutaneous occlusion with coils of coronary artery fistulas in adults [in Spanish]. Rev Esp cardiol 2005; 58 (1): 93-6.

15. Khan MD, Qureshi SA, Rosenthal E, Sharland GK. Neonatal transcatheter occlusion of a large coronary artery fistula with Amplatzer duct occluder. Catheter Cardiovasc Interv 2003; 60(2): 282-6.
16. Pedra CA, Pihkala J, Nykanen DG, Benson LN Antegrade transcatheter closure of coronary artery fistula using vascular occlusion devices. Heart 2000; 83 (1): 94-6.

17. Meier B. Coronary occlusion after failed closure of coronao-pulmonary fistula with detachable balloon. Cathet Cariovasc Diagn 1989; 18 (4): 237-9.

18. Lacombe P, Rocha P, Marchand X, Mulot R, Rigaud M, Jondeau G, et al. High flow coronary fistula closure by percutateous coil packing. Cathet Cardiovasc Diagn 1993; 28 (4): 342-6.

19. Okubo M, Nykanen D, Benson LN. Outcomes of transcatheter embolization in the treatment of coronary artery fistulas. Catheter Cardiovasc Interv 2001; 52 (4): 510-7. 